\title{
Assessing the Quality Land Administration System in Pakistan Using Systematic Approach of Case Study Methodology
}

\author{
Zahir Ali ${ }^{1,2,}$, Jaap Zevenbergen ${ }^{2}$, Arbind Tuladhar ${ }^{2}$ \\ ${ }^{1}$ Pakistan Space and Upper Atmosphere Research Commission (SUPARCO), Karachi, Pakistan \\ ${ }^{2}$ Faculty of Geo-Information Science and Earth Observation, University of Twente, AE Enschede, the Netherlands \\ *Corresponding author: drzahirali@hotmail.com
}

Received May 28, 2014; Revised July 11, 2014; Accepted July 21, 2014

\begin{abstract}
Land Information System is a tool for legal, administrative and economic decision making as well as an aid for planning and development. The present land administration system in Pakistan is entirely based on paper land records and maps lacking standards with outdated information stored at different administrative levels. Such practice restricts the usefulness of reliable and quality land information for supporting tenure security to citizens, socioeconomic development, and urban/rural development including infrastructure. This situation demands for a methodological framework to assess the quality of the existing system before going to take necessary action for quality improvement. There have been a few efforts to standardize the procedures for assessing the quality of land administration systems at international level but there is no internationally accepted or standardized method to assess the quality of a standalone land administration system within a country's environment. To be able to assess the quality of a standalone land administration system, this paper develops a methodological framework for assessing the quality of the existing land administration system in the Khyber Pakhtunkhwa province of Pakistan through systematic use of case study methodology including both exploratory and explanatory case study approaches. The main outcomes of this research leads to a standardized framework that can be used for assessing the quality of a standalone land administration system within a country's environment.
\end{abstract}

Keywords: land administration system, quality assessment, case study methodology, exploratory case study, explanatory case study

Cite This Article: Zahir Ali, Jaap Zevenbergen, and Arbind Tuladhar, "Assessing the Quality Land Administration System in Pakistan Using Systematic Approach of Case Study Methodology.” American Journal of Rural Development, vol. 2, no. 3 (2014): 40-45. doi: 10.12691/ajrd-2-3-1.

\section{Introduction}

Research in the area of cadastre and land administration systems is increasingly using the information system's research methodologies [1-11]. Studies in this area have been carried out using different research methodologies such as soft system methodology, case study methodology, etc. Silva and Stubkjær [12] outlined in their study that the methodologies used in cadastral research are largely those of the social sciences. That agrees with the notion that cadastre and land administration system (LAS) relate as much to people as it relates to land, and that cadastral and land administration systems are shaped by social, political and economic conditions, as well as by legal and technological factors. This research further prevails that a case study methodology is used as a research method in most of the cadastral research studies, which proves the effectiveness of case study methodology in cadastral research.

A case study is an examination of the phenomenon in which the primary purpose of the observer has been to carry out research rather than to implement a system or improve an operational environment [13]. Case study is an ideal methodology when a holistic and in-depth investigation is needed $[14,15]$. The analysis of a land administration system also requires an in-depth investigation and a holistic approach to consider all aspects of the existing system.

The intention of this paper is to develop a framework for systematic use of both exploratory and explanatory case study approaches for assessing the quality of LAS. The case of LAS in Pakistan is presented and discussed in this paper using an explanatory case study approach to understand the present status of LAS in the country. Qualitative and quantitative data are collected in urban and rural areas of Peshawar and Swabi districts of the Khyber Pakhtunkhwa province of Pakistan.

\section{Theoretical Background}

Case study research can be positivist, interpretive or critical. Positivist case study research can be descriptive, exploratory (theory building) or explanatory (theory 
testing) and each of those three approaches can be either single or multiple-case studies [16]. An exploratory case study, whether based on single or multiple cases, is aimed at defining questions, constructs, propositions or hypotheses to be the object of a subsequent empirical study [15]. Exploratory case study can provide a basis for further investigation and analysis to include all the parameters of a system to be studied through an explanatory case study.

\subsection{Exploratory Case Study}

Exploratory research provides insights into and knowledge of an issue or situation drawing the definitive conclusions only with extreme caution. Exploratory research is a type of research conducted when the problem has not been clearly defined. It helps to determine the best research design, data collection method and selection of subjects [17]. Exploratory research studies are also termed as formulative research studies. The main purpose of such studies is that of formulating a problem for more precise investigation. The major emphasis in such studies is mostly on the discovery of ideas and insights [18]. These ideas and insights provide a line of action for further investigation.

According to Creswell [19], "exploratory case study means that not much has been written about the topic or the population being studied, and the researcher seeks to listen to participants and build an understanding based on their ideas.” Exploratory case studies involve original field interviews on a limited scale with interested parties and individuals with a view to secure greater insight into the practical aspects of the problem [18]. Exploratory research uses a less formal approach. It pursues several possibilities simultaneously and in that sense it is not quite certain of its objective. In other words, exploratory case study provides a background, to familiarise the general subject. It investigates the relationships among variables without knowing why they are studied.

Since an exploratory case study does not have a hypothesis to start with, the findings of such a study have to be interpreted on a post-factum basis. The findings of exploratory case study often result into hypotheses for experimental research [18]. Creswell [19] argues that for an exploratory case study, the use of a qualitative approach is considered appropriate. However, the questions outlined through exploratory case study can be further explained through an explanatory case study approach to investigate a system in more detail.

\subsection{Explanatory Case Study}

Explanatory research attempts to clarify why and how there is a relationship between two aspects of a situation or phenomenon [20]. Stake [21] defines explanatory case study research as a disciplined, qualitative form of inquiry into the single case, the aim of which was to understand and emphasise the complexity and uniqueness of that case. Yin [15] described the applications of explanatory case study as a research tool across the social science disciplines, in both the traditional fields such as psychology, sociology and anthropology as well as the practice-orientated fields of urban planning, public administration, public policy, management science, social work, and education.
Explanatory case studies are useful when conducting causal studies such as the performance evaluation of a system. Particularly in complex studies of organisations or communities, one might desire to employ multivariate cases to examine a plurality of influences [22]. Fisher and Ziviani [23] concluded that "An explanatory case study design provides a contemporary framework, which extends beyond the traditional descriptive and explorative case study avenues, enabling cases to be used with greater rigour in research as a tool to support or refute hypotheses and develop theoretical models." In this way the use of an explanatory case study enables the researcher to develop a theoretical framework and then justify it through analysing the qualitative and quantitative data being collected in the case study. This can further help to strengthen this theoretical framework after analysing the collected data.

\subsection{Stages of Case Study Methodology}

Yin [15] recommended four stages for a case study methodology:

- Designing the case study

- Conducting the case study

- Analysing the case study evidence

- Writing the case report and research implications.

\subsubsection{Designing the Case Study}

The design is the logical sequence that connects the empirical data to a study's initial research questions and, ultimately, to its conclusions. In other words, a design is an action plan for getting from here to there, where 'here' may be defined as the initial set of questions to be answered, and 'there' is some set of conclusions (answers) about these questions. A number of major steps, including the collection and analysis of the relevant data may be found between 'here' and 'there' [15].

In an exploratory case study research, which merely leads to insights, the case study design must continue to remain flexible so that many different facets of a problem may be considered as and when they arise and come to the notice of the researcher. However, the research design in case of descriptive studies must be rigid to make enough provision for protection against bias for maximising reliability, with due concern for economical completion of the study [18].

Five important components are pointed out by Yin [15] to design a case study which include;

- A study's questions

- Its propositions, if any

- Its unit(s) of analysis

- The logic linking the data to the propositions

- The criteria for interpreting the findings.

Formulation of a study's questions is the first task of a researcher. Designing one or more related research questions, in at least broad terms, is as important in building theory from case studies as it is in hypothesistesting research [16]. The form of question - in terms of 'who', 'what', 'where', 'how', and 'why' - provides an important clue regarding the most relevant research strategy to be used [15].

The study's propositions are sometimes derived from the study's questions, and are helpful in focusing the study's goals. Each proposition directs the attention to 
something that should be examined within the scope of the study. Not all studies need to have propositions. An exploratory study, rather than having propositions, would have a stated purpose or criteria on which the success will be judged $[15,24]$.

The definition of the unit of analysis (and therefore of the case) is related to the way the initial research questions have been defined. The unit of analysis defines what the case is. It is the actual source of information which may be an individual, organisational document, and artefact (e.g. the capital flow between countries, an economic policy). Selection of the appropriate unit of analysis results from accurately specifying the primary research questions. If the questions do not lead to the favouring of one unit of analysis over another then the questions are probably either too vague or too numerous [15].

Linking the data to propositions and to the criteria for interpreting the findings are the components that have been the least well developed in case studies. These components represent the data analysis steps in case study research, and a research design should lay a solid foundation for this analysis [15].

\subsubsection{Conducting the Case Study}

Conducting the case study is the most important and difficult stage. If not done well, the entire case study investigation can be endangered, and all of the earlier work - in defining the research questions and designing the case study - will have been for nothing. The preparation for doing a case study includes the prior skills of the investigator, the training and preparation for the specific case study, the development of a case study protocol, and the conduct of a pilot case study [15]. This is the next stage of case study methodology in which the data is collected in the field.

Case study research typically combines multiple data collection methods. Collecting different types of data by different methods from different sources produces a wider scope of coverage and may result in a fuller picture of the phenomena under study than would have been achieved otherwise [25]. Data collection for case studies can rely on many sources of evidence. The six important sources of evidence are identified in case research which are documentation, archival records, interviews, direct observation, participant observation, and physical artefacts $[15,21]$. Not all need to be used in every case study. No single source has a complete advantage over the others [15]. However, the selection of these different sources depends upon the nature of the research questions and case study approach to be used.

\subsubsection{Analysing Case Study Evidence}

Data represent the fruit of a researcher's labour because they provide the information that will ultimately allow him to describe phenomena, predict events, identify and quantify differences between conditions, and establish the effectiveness of interventions. Because of their critical nature, data should be treated with the utmost respect and care. If a study has been conducted in a scientifically rigorous manner, the data will hold the clues necessary to answer the researchers' questions [26]. Therefore, the data acquired in a case study through different sources of evidences should be analysed carefully to answer the research questions and ultimately fulfil the objectives of the research.

The analysis of case study evidence is one of the most difficult aspects of doing case studies. Data analysis consists of examining, categorising, tabulating, or otherwise recombining the evidence to address the initial propositions of a study. Case studies tend to produce large amounts of data that are not readily amenable to mechanical manipulation, analysis, and data reduction [15]. The basic goal of qualitative data analysis is understanding, i.e. the search for coherence and order [27]. This is the most difficult aspect of case study methodology. Different analytical techniques such as creating flowcharts, matrices, data displays, and tabulation can be used to facilitate data analysis [28]. After analysing case study evidence, a clear picture of a studied system can be drawn for further improvement.

\subsubsection{Writing the Case Report and Research Implications}

The reporting aspect of a case study is perhaps most important from the user (reader) perspective. It is the contact point between the user and the researcher. A welldesigned research work that is not well explained to the reader will cause the research report to fall into disuse [16]. A case report deals with the results of a completed case study. It is generally produced in the written form and is called case report. It is a matter of communicating what was done, what occurred, and what the results mean in a concise, understandable, accurate and logical manner [29].

Reporting a case study means bringing its results and findings to closure. It is one of the most challenging aspects of doing case studies. The case study 'report' does not follow any stereo-typical form, such as a journal article. Different alternatives exist for structuring case study 'reports' as per case study requirements. These alternatives include linear-analytic structures, comparative structures, chronological structures etc. The sequence of linear-analytic structures involves the issue or problem being studied, a review of the relevant prior literature, the methods used, the findings from the data collected and analysed, and the conclusions and implications from the findings [15]. It is the most important step of a case study methodology in which the final conclusions are drawn after analysing the case study evidence.

\section{Study Area and Methodology}

Table 1. Fact sheet about Khyber Pakhtunkhwa province

\begin{tabular}{|l|l|}
\hline Capital: & Peshawar \\
\hline Area: & 74,521 sq.km \\
\hline Population: & $20,215,000$ (2008 Estimated) \\
\hline Density: & $270 / \mathrm{km}^{2}$ \\
\hline Languages: & Pashto, Saraiki, Urdu and Hindko \\
\hline Literacy Rate: & $49.9 \%$ \\
\hline Administrative Division: & 7 \\
\hline Districts: & 24 \\
\hline Tehsils: & 90 \\
\hline Kanungo Circles: & 115 \\
\hline Patwar Halqas: & 1227 \\
\hline Mauzahjat: & 4335 \\
\hline Revenue Courts: & 5 \\
\hline Source: Wikipedia [30] and BOR \\
\hline
\end{tabular}


The land administration organisation called Board of Revenue (BOR), in the Khyber Pakhtunkhwa (formerly called NWFP) province of Pakistan was chosen in this research for assessing the quality of the existing LAS. Some facts about the Khyber Pakhtunkhwa (KP) province are given in Table 1.

The collected data comprised interviews with all the stakeholders including law professionals, land owners, real estate agencies, revenue courts and banks officials, as well as visits to the Board of Revenue (BOR) offices at Peshawar and Swabi districts to meet with the BOR officials and staff [31,32,33].

The BOR offices at the Peshawar and Swabi districts of $\mathrm{KP}$ province were visited during the field visits. The locations of these districts on the provincial map are shown in Fig 1. Peshawar is the provincial capital city of $\mathrm{KP}$ province, and BOR has its provincial headquarters in this city. Swabi is a district city and BOR has its office at district level in this city. Meetings and interviews were arranged with the BOR officials at the headquarters in Peshawar city. This included; Senior Member Board of Revenue (SMBR), Member Board of Revenue (MBR), and Director Land Records (DLR). The other BOR officials such as Tehsildar, Naib Tehsildar, and Patwari were also interviewed in these two districts to note down their concerns about the existing system.

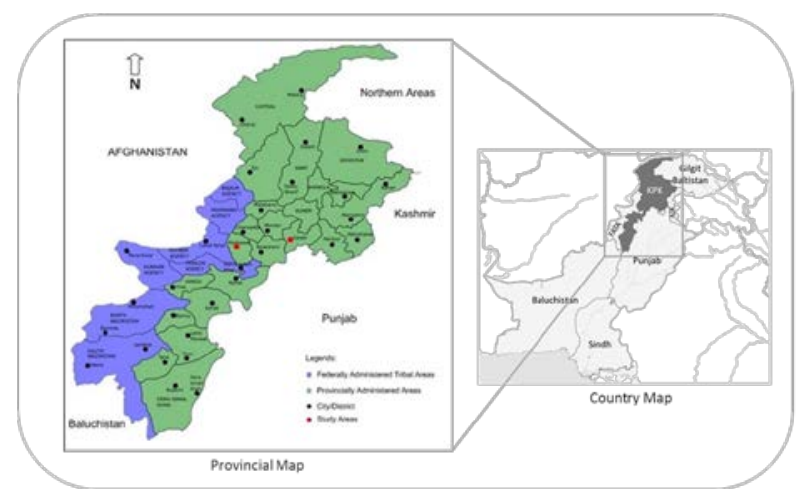

Figure 1. Location of fieldwork study areas

In order to do the holistic analysis of existing LAS in the study area, this research considered the systematic use of exploratory and explanatory case study approaches for collecting the qualitative as well as quantitative data, as shown in Figure 2.

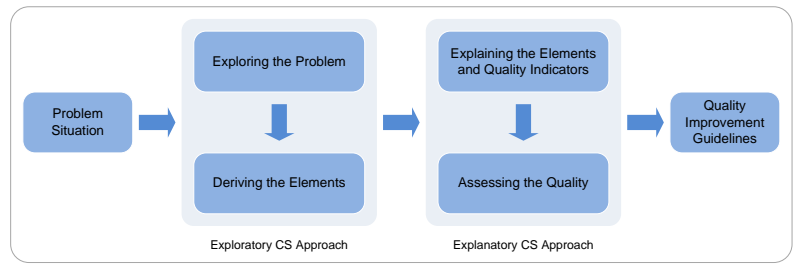

Figure 2. Methodological framework for using CSM

The exploratory case study approach was used to explore the problems of the existing LAS and then defining elements and indicators for further analysis. When the elements and quality indicators of the existing LAS were defined, an explanatory case study approach was then used to analyse the status of these quality indicators in more detail. At the end the quality situation of the existing LAS in the study area is presented after analysing the results obtained.
Two field visits were carried out in this research to collect the data in the field for analysing and exploring the existing situation of LAS in Pakistan. These two case study approaches took into account all the organisational levels (policy, management, operational) of land administration agency through interaction with all stakeholders to collect sufficient information for in-depth analysis of the existing system.

In order to understand the present status of the quality indicators and variables in the existing LAS, some structured and semi-structured interviews were conducted with land administration officials at policy level, management level and operational level in the study area. Furthermore, detailed questionnaires were also distributed among 235 stakeholders including BOR officials, law professionals, land owners, real estate agencies, revenue courts and banks officials, to understand the present status of the quality indicators and variables in more detail. The data were collected from a cross-section of different stakeholders in urban and rural areas of the Peshawar and Swabi districts.

\subsection{Exploratory Case Study Approach}

An exploratory case study approach was used in the first field visit to collect data in the study areas to understand the issues of existing LAS by exploring the important elements of the system [32]. To understand the existing situation of LAS in the study area, some critical questions were brought into consideration to make this case study research focused and more effective. These research questions were explored in this exploratory case study to develop a conceptual framework for LAS quality assessment in the study area as per country's environment. A set of questionnaires were designed to analyse the present situation of LAS in the study area. These questionnaires were distributed among different stakeholders including; lawyers, land owners, and land administration staff to get a clear picture of the present system for finding the indicators contributing to the quality assessment framework.

In this study, three sources were frequently used to provide data for this case study. These were (a) interviews, (b) analysis of archival documents, and (c) participant's observations. These sources were used during the field visit to get a clear picture of the present LAS in the study area. Data was collected through interviews (structured and semi-structured) with all the stakeholders during office visits at Board of Revenue (BOR) headquarters and district offices to gain full understanding of the present situation of LAS in the country especially in the study area. To understand the actual practices carried out by the land administration staff in the field, some visits were also carried out in the field. Other information about the existing system were also collected through literature review and interviews with different stakeholders including; farmers, lawyers, and BOR personals in the study area.

During the data collection process, a variety of techniques including structured and semi-structured interviews with individuals and groups were applied to collect the data in the field. The qualitative data were collected through review of historical documents, official reports, and news articles. On the preliminary analysis of this qualitative data, appropriate questionnaires were then designed during the field visit to get quantitative data. 
These questionnaires were designed on the basis of LAS issues to analyse the present situation of the system in study area. These questionnaires were distributed among the stakeholders to get deep understanding of the existing system. This investigation aided in developing a conceptual quality assessment framework for assessing the quality of existing LAS.

\subsection{Explanatory Case Study Approach}

An explanatory case study approach is used in the second field visit to explain the quality situation of the existing LAS for the most important elements (explored in the first case study) as well as other contributing elements through their indicators and variables. The second field visit was also conducted in the study areas to collect both qualitative and quantitative data through visits, interviews, and questionnaire surveys [33]. This included interviews with the stakeholders including; land owners, law professionals, real estate agencies, revenue courts, and banks officials, as well as visits to the BOR offices in these districts to meet with BOR officials and staff.

To understand the present status of these indicators for existing LAS in the study area, again some structured and semi-structured interviews were also conducted with land administration officials including; SMBR, MBR, Sectary, DLR, Tehsildars, Naib-Tehsildars, and Patwaries being working at different organisational levels. Both qualitative and quantitative data was collected from the cross-section of different stakeholders in urban and rural areas of these districts. All the stakeholders were proportionally sampled in each district to achieve an appropriate distribution of data sample. The qualitative data was collected through interviews (structured and semi-structured) with stakeholders including; land administration agency officials, land owners, and law professionals while the quantitative data was collected through structured questionnaires distributed among all the stakeholders.

An in-depth analysis of collected data was carried out to understand the present status of these quality indicators in the study area. The analysis of this data provided an indepth understanding of these quality indicators in existing LAS. This investigation helped in assessing the quality situation of existing LAS in the study area.

Table 2. Quality situation of LAS in Pakistan

\begin{tabular}{|l|l|}
\hline Elements & Quality Situation \\
\hline Tenure security & Unclear \\
\hline Land policy & Unclear \\
\hline Legal framework & Complex \\
\hline Land dispute resolution & Complex \\
\hline Organisation and mandates & Clear \\
\hline Human resource development & Inadequate \\
\hline Land administration processes & Complex \\
\hline Data organisation & Inadequate \\
\hline Coordination and data sharing & Clear \\
\hline Financing and data cost & Inadequate \\
\hline Strategic plans & Unclear \\
\hline Users' needs & Inadequate \\
\hline Technology adoption & Inadequate \\
\hline Training and development & Inadequate \\
\hline Land information system design & Unclear \\
\hline Workflows for LA processes & Unclear \\
\hline Quality standards & Inadequate \\
\hline Services and products & Inadequate \\
\hline
\end{tabular}

\section{Quality Situation of LAS}

This assessment identified the quality situation of the existing LAS in the study area. The existing quality situation of LAS in KP province, as identified for different elements LAS, is summarised in Table 2.

This assessment highlighted all the contributing issues for improving the quality to overcome these issues and ultimately improve the quality of land administration system.

\section{Conclusions}

The increasing demands as a result of environmental issues and technological developments demand that the administration and management of land should be done in an efficient, transparent and integrated manner. Land administration systems have to respond to such needs through appropriate and efficient tools. The development of a quality assessment framework to investigate the quality of existing LAS is a very helpful tool. However, the assessment is more meaningful when it is based on a standardised approach to investigate the objectives and issues of the existing system in a holistic manner. This study has developed a conceptual and methodological framework for analysing the quality of a standalone LAS. The systematic use of case study methodology (exploratory-explanatory case study approach) provided a methodological framework to do in-depth analysis of a land administration system. This was impossible by using either exploratory or explanatory case study approach in isolation. This methodological framework maximised the capabilities of case study approach in analysing the quality of a standalone land administration system within a country's environment.

\section{Acknowledgement}

We wish to gratefully acknowledge Mr. Nouman Shah Jadoon (SMBR), Mr. Kifayatullah Khan (DLR), Mr. Ajmal Bhatti (Secretary), and other stakeholders interviewed from the Board of Revenue for their guidance and assistance with data collection. We also acknowledge Mr. Tayyeb Zaman Advocate from Swabi District Bar Council and Mr. Mir Sardar Afridi from Peshawar District for their dedicated and enthusiastic co-operation in quantitative data collection for this work. Finally, we would like to thank the International Institute for GeoInformation Science and Earth Observation (ITC), the Netherlands, The Higher Education Commission (HEC) of Pakistan and the Netherlands Organization for International Cooperation in Higher Education (NUFFIC) for providing this research opportunity and funding assistance.

\section{References}

[1] Barry, M., Evaluating cadastral systems in periods of uncertainty: a study of Cape Town's Xhosa - speaking communities, in University of Natal. 1999, University of Natal: Durban. p. p. 360.

[2] Bittner, S., A.V. Wolff, and A.U. Frank, The Structure of Reality in a Cadaster, in 23rd International Wittgenstein Symposium 
(Rationality and Irrationality). 2000, Austrian Ludwig Wittgenstein Society: Kirchberg am Wechsel, Austria. p. pp. 8896.

[3] Castanyer, J. and I. Canet, El Catastro in Europa. 1990, Ministerio de Economia y Hacienda: Madrid.

[4] Fourie, C. and H. van Gysen, Constructing cadastral reform theory in South Africa. Geomatica, 1995. 49(3): p. pp. 315-328.

[5] Steudler, D., et al., Benchmarking cadastral systems. The Australian Surveyor, 1997. 42(3): p. pp. 87-106.

[6] Stubkjær, E. Real estate and the ontology of multidisciplinary, e.g. cadastral, studies. in Euro Conference on ontology and epistemology for spatial data standards. 2000. Vienna: University of Technology.

[7] Tan, W., The development of cadastral systems: an alternative view. The Australian Surveyor, 1999. 44(2): p. pp. 159-164.

[8] Ting, L. and I.P. Williamson, Cadastral Trends: A Synthesis. The Australian Surveyor, 1999. 44(1): p. pp. 46-54.

[9] Williamson, I.P. and C. Fourie, Using the Case Study Methodology for Cadastral Reform. Geomatica, 1998. 52(3): p. pp. 283-295.

[10] Williamson, I.P. and L. Ting, Land administration and cadastral trends -- a framework for re-engineering. Computers, Environment and Urban Systems, 2001. 25(4-5): p. pp. 339-366.

[11] Zevenbergen, J.A., Systems of land registration: Aspects and Effects, in Netherlands Geodetic Commission NCG : Publications on Geodesy : New Series; 51. 2002, TU Delft: Delft. p. p. 223.

[12] Silva, M.A. and E. Stubkjær, A review of methodologies used in research on cadastral development. Computers, Environment and Urban Systems, 2002. 26(5): p. pp. 403-423.

[13] Onsrud, H.J., K.P. Jeffrey, and B. Azad, Case Study Research methods for Geographic Information Systems. Urban and Regional Information Systems Association (URISA), 1992. 1(Spring(Part 4)): p. pp. 32-43.

[14] Feagin, J., A. Orum, and G. Sjoberg, A case for case study. 1991, University of North Carolina Press: Chapel Hill, NC.

[15] Yin, R.K., Case study research: design and methods. Third Edition ed. Applied social research methods series. 2003 Newbury Park: Sage Publications. p. 170.

[16] Paré, G., Using A Positivist Case Study Methodology to Build and Test Theories in Information Systems: Illustrations from Four Exemplary Studies. 2001, Groupe de recherche en systèmes d'information (GReSI).

[17] Wikipedia. Exploratory Research. 201015 March 201029 March 2010]; Available from: http://en.wikipedia.org/wiki/Exploratory_research.

[18] Kothari, C.R., Research Methodology: Methods And Techniques. Second Revised Edition ed. 2004: New Age International. p. 418.
[19] Creswell, J.W., Qualitative Inquiry and Research Design: Choosing Among Five Approaches. Second Edition ed. 2007: Sage Publications. p. 416.

[20] Kumar, R., Research methodology: a step-by-step guide for beginners. Second Edition ed. 2005, Frenchs Forest, N.S.W.: Pearson Longman. p. 326.

[21] Stake, R., The art of case research. 1995, Thousand Oaks, CA: Sage Publications. p. 192.

[22] Berg, B.L., Qualitative Research Methods for the Social Sciences. Fourth Edition ed. 2001, Boston, Mass, London: Allyn and Bacon. p. 304.

[23] Fisher, I. and J. Ziviani, Explanatory case studies: Implications and applications for clinical research. Australian Occupational Therapy Journal, 2004. 51(4): p. pp. 185-191.

[24] Tellis, W., Application of a case study methodology. The Qualitative Report, 1997. 3(3)

[25] Bonoma, T.V., Case Research in Marketing: Opportunities, Problems, and a Process. Journal of Marketing Research, 1985. 22: p. pp. 199-208.

[26] Marczyk, G.R., D. DeMatteo, and D. Festinger, Essentials of Research Design and Methodology. 2005: John Wiley \& Sons. p. 290

[27] Kaplan, B. and J. Maxwell, Qualitative Research Methods for Evaluating Computer Information Systems, in Evaluating the Organizational Impact of Healthcare Information Systems. 2005, Springer: New York. p. pp. 30-55.

[28] Miles, M. and M. Huberman, Qualitative data analysis: A source book for new methods. 1984, Thousand Oaks, CA: Sage Publications. p. 256.

[29] Singh, Y.K., Fundamentals of Research Methodology and Statistics. First Edition ed. 2006: New Age International. p. 322

[30] Wikipedia. Khyber Pakhtunkhwa. 201226 August 2012 at 21:26 [cited 201227 August 2012]; Available from: http://en.wikipedia.org/wiki/Khyber Pakhtunkhwa.

[31] Ali, Z. and A. Nasir. Land Administration System in Pakistan Current Situation and Stakeholders' Perception. in FIG Congress 2010: Facing the Challenges - Building the Capacity. 2010. Sydney, Australia.

[32] Ali, Z., A.M. Tuladhar, and J.A. Zevenbergen, Developing a Framework for Improving the Quality of a Deteriorated Land Administration System Based on an Exploratory Case Study in Pakistan. Nordic Journal of Surveying and Real Estate Research, 2010. 7(1): p. pp. 30-57.

[33] Ali, Z., J. Zevenbergen, and A. Tuladhar, Quality assessment of the land administration system in Pakistan. Journal of Spatial Science, 2013. 58(1): p. pp. 119-146. 